\title{
Inhalation Vapor, Tablet Dosage Form
}

National Cancer Institute

\section{Source}

National Cancer Institute. Inhalation Vapor, Tablet Dosage Form. NCI Thesaurus. Code C149591.

Solid preparation consisting of a tablet intended for generation of vapor to be inhaled to obtain a local effect. The vapor is usually generated by adding the tablet to hot water. 